\title{
Profiles of sensitization and comorbidity in asthma patients with markedly increased serum total immunoglobulin E level (>1000 kUA/L)
}

\section{Ge Wu}

Guangzhou Medical College First Affiliated Hospital

\section{Teng Zhang}

University of Macau

Xiaohua Douglas Zhang

University of Macau

Baoqing Sun ( $\square$ sunbaoqing@vip.163.com )

University of Macau https://orcid.org/0000-0002-1671-0723

\section{Research}

Keywords: Asthma, immunoglobulin E, atopy, comorbidity

Posted Date: February 12th, 2021

DOI: https://doi.org/10.21203/rs.3.rs-212197/v1

License: (c) (i) This work is licensed under a Creative Commons Attribution 4.0 International License. Read Full License 


\section{Abstract}

\section{Background}

Immunoglobulin E (IgE) plays an important role in asthma, but a few cases exhibited extremely high levels of serum total IgE. This study aimed to investigate the profiles of complications, severity, and sensitizations in asthma patients with serum total lgE level $>1000 \mathrm{kU}_{\mathrm{A}} / \mathrm{L}$.

\section{Methods}

We retrospectively analyzed 170 asthma patients with serum total IgE levels $>1000 \mathrm{kU}_{\mathrm{A}} / \mathrm{L}$ from the inpatient database of First Affiliated Hospital of Guangzhou Medical University from January 2014 to June 2019. Available information including age, gender, body mass index (BMI), diagnosis, results of blood routine, pulmonary function, fractional exhaled nitric oxide (FeNO), induced sputum (if any), lgE (both total and specific) and medication records were analyzed.

\section{Results}

About $15 \%$ patients had at least one complication, and $78.82 \%$ patients were positive for at least one allergen. The top two complications were airway infections (44.71\%) and rhinosinusitis $(41.18 \%)$, followed by hypertension and/or cardiovascular diseases (20.59\%) and COPD (12.94\%). And in patients without sensitization, rhinosinusitis accounted for the highest proportion over all complications (45.83\%). Serum total IgE levels did not differ among patients with different complications. Overall, mites had the highest positive rate $(59.4 \%)$. In minors, the positive rates of mites $(81.25 \%$ vs. $54.35 \%, P<0.01)$ and food $(68.75 \%$ vs. $39.86 \%, P<0.01)$ were significantly higher than those in adults. Serum total IgE levels were positively correlated to house dust mite specific IgE levels $(\mathrm{r}=0.23, P<0.05)$, peripheral blood eosinophil counts $(r=0.21, P<0.01)$ and number of confirmed slgE positivity $(\mathrm{r}=0.19, P<0.01)$ and optimal scaling analysis showed that asthma severity was associated with $A$. fumigatus specific lgE levels.

\section{Conclusions}

In asthma patients with markedly increased serum total IgE levels $\left(>1000 \mathrm{kU}_{\mathrm{A}} / \mathrm{L}\right)$, the most common two complications were airway infections and rhinosinusitis despite of sensitization. A. fumigatus specific IgE levels were closely associated with total IgE levels and asthma severity.

\section{Background}

Asthma is a chronic inflammatory disease of the airways with the typical characteristics of reversible airflow limitation and airway hyperresponsiveness (AHR) [1]. Its clinical symptoms vary from individuals, including wheeze, shortness of breath, dyspnea, chest tightness and/or cough. Asthma has been a public health issue over all ages worldwide, affecting $1-18 \%$ of the population in different countries, and the economic burden of the disease is still on the rise [2,3]. Allergic asthma is the most common phenotype [4], in which T helper type 2 inflammation is considered to be the predominant immune response against 
the allergens encountered [5]. Antigen presenting cells (APCs) with captured allergen leads to the activation of T helper 2 (Th2) cells, resulting in the secretion of Th2 cytokines such as interleukin-4 (IL-4) and IL-13. Afterwards, B cell is stimulated for immunoglobulin E (IgE) synthesis and secretion. The secreted IgE can not only binds to mast cells, which triggers degranulation, consequently causing allergic symptoms, but binds to APCs and activates more Th2 cells.

In fact, most cases of asthma contributes to lgE-mediated reaction, and the increased levels of total and specific $\lg E$ in the peripheral is involved in the onset as well as the chronic phase of the disease [6]. Studies have indicated that elevated serum total IgE levels could occur in atopic and non-atopic asthma patients, and it was associated with the risk of asthma as well as with AHR [7-9]. However, the correlation between IgE level and asthma severity is controversy. Borish $L$ et al.'s study found that children with severe asthma had high serum IgE level, while another did not find a significant association between total IgE levels and disease severity $[10,11]$. This can be affected by several factors, such as polysensitization, non-allergenic factors (e.g. infection) and persistent inflammation caused by allergens [12]. Despite of that, anti-IgE treatment has been applied in clinical practice for some cases of poorly controlled moderate-to-severe asthma, which improves asthma related symptoms and reduces severe exacerbations $[13,14]$.

There are a few patients exhibited extremely high levels of serum total $\lg \mathrm{E}\left(>1000 \mathrm{kU}_{\mathrm{A}} / \mathrm{L}\right)$. Conditions like atopic eczema, helminthic infection and rare primary immunodeficiencies can lead to markedly upregulated total lgE levels (>1000 kU $/$ /L) [15]. In some of these cases with sensitization of Aspergillus fumigatus, they might develop allergic bronchopulmonary aspergillosis (ABPA) as Th2 immunity against the fungi increased $[16,17]$. The prevalence was estimated to be about $6 \%$ in chronic cases of asthma, and total $\lg \mathrm{E}>1000 \mathrm{kU}_{\mathrm{A}} / \mathrm{L}$ is considered as one of the diagnostic criteria of ABPA $[18,19]$. However, certain amount of asthma patients with total $\lg \mathrm{E}>1000 \mathrm{kU}_{\mathrm{A}} / \mathrm{L}$ do not meet the diagnostic criteria of ABPA. To date, few study has been performed to investigate these asthma cases. In order to better understand the characteristic of these cases, we aimed to analyze the profiles of complications, severity, and sensitizations in asthma patients with serum total $\lg \mathrm{E}>1000 \mathrm{kU}_{\mathrm{A}} / \mathrm{L}$.

\section{Methods}

\subsection{Study subjects}

This is a retrospective analysis of the in-patient database generated by First Affiliated Hospital of Guangzhou Medical University, from January 2014 to June 2019. We screened the database for patients who were clinically diagnosed as asthma and had serum total lgE levels $>1000 \mathrm{kU}_{A} / \mathrm{L}(\mathrm{n}=202)$. Patients met the diagnostic criteria of ABPA based on The International Society of Human and Animal Mycology (ISHAM) working group were excluded [18]. A total of 170 asthma patients with total $\operatorname{lgE}>1000 \mathrm{kU}_{\mathrm{A}} / \mathrm{L}$ were screened out from the database (Figure S1). Among the included subjects, 24 patients had hospitalization records for more than one time during the study period. The data used for analysis was the data of the patients when total $\lg \mathrm{E}>1000 \mathrm{kU}_{\mathrm{A}} / \mathrm{L}$ was first recorded among their hospitalizations. None 
of the included patients had diagnosis of primary immunodeficiency diseases. Available information of each patient were collected for analysis, including age, gender, body mass index (BMI), diagnosis, results of blood routine, pulmonary function, fractional exhaled nitric oxide (FeNO), induced sputum (if any), lgE (both total and specific) and medication records.

\subsection{Diagnosis criteria and disease classification}

The diagnosis of asthma was based on the Global Initiative for Asthma (GINA) guidelines, including asthma clinical features of the patient as well as presence of airflow limitation. The diagnosis of chronic obstructive pulmonary disease (COPD) was based on the Global Initiative for Chronic Obstructive Lung Disease (GOLD) guidelines, including presence of clinical features like dyspnea, chronic cough or sputum production and meeting the spirometry standard. The diagnosis of eosinophilic granulomatosis with polyangiitis (EGPA) was based on the criteria developed by Lanham et al., including asthma, peak eripheral blood eosinophil count $>1.5 \times 10^{9}$ cells $/ L$ and systemic vasculitis involving two or more extrapulmonary organs [20]. The definition of rhinosinusitis was according to the European position paper on Rhinosinusitis and nasal polyps, which contains characterized symptoms, endoscopic signs and CT changes [21]. Cardiovascular diseases (CDVs) included coronary heart disease, cerebrovascular disease, peripheral arterial disease, rheumatic heart disease, congenital heart disease and deep vein thrombosis and pulmonary embolism. Hypertension was diagnosed following WHO's instruction, which is on two different days, the systolic blood pressure readings was $\geq 140 \mathrm{mmHg}$ and/or the diastolic blood pressure readings was $\geq 90 \mathrm{mmHg}$. The diagnosis of cancer was confirmed via pathological diagnosis of the lesions. Airway infection includes pneumonia, bronchi infections and lung infections caused by microorganisms.

\subsection{Grouping}

Since some of the complications (e.g. COPD) as well as sensitization profiles (food sensitization may decrease as children grew up [22]) varied from ages, patients were classified into minors (age <18, $n=32$ ) and adults (age $\geq 18, n=138$ ) for our analysis. The assessment of asthma severity was based on the level of treatment required to control symptoms and exacerbations of the past 4 weeks following the instruction of GINA guideline [3]. Briefly, mild asthma is well controlled with Step 1 or Step 2 treatment; moderate asthma is well controlled with Step 3 treatment; severe asthma requires Step 4 or 5 treatment to prevent it from becoming 'uncontrolled', or remains 'uncontrolled' despite this treatment. The severity assessment was recorded in the medical records of each patient by specialists, and those who lacked such information were not available for assessing severity. Among the enrolled patients, 27 (15.88\%) were with mild asthma, 68 (40\%) were with moderate asthma, $55(32.35 \%)$ were with severe asthma and 20 patients $(11.76 \%)$ lacked information for asthma severity assessment.

\section{$2.4 \lg$ E detection}

Serum samples were obtained from venous blood collecting with separation gel containing vacutainer tubes by centrifuged at 3000rpm for 10min. Serum total IgE and specific IgE (including Phadiatop test 
[23], allergen mixtures such as house dusts mix (hx2) and specific allergens) were analyzed by ImmunoCAP 1000 system (Thermo Fisher Scientific Inc., California, USA) according to the procedures offered by the manufacture. The tests of patients undergoing were depended on the allergy history of each patient and were prescribed by specialists. A positive result of specific IgE was considered as $\geq 0.35$ $\mathrm{kU}_{\mathrm{A}} / \mathrm{L}$. For those patients who were positive for Phadiatop or allergen mixtures but did not take further detection of specific IgE of typical allergens, they were considered as sensitized to at least one inhaled allergen or at least one of the mixture allergens, respectively. IgE detection was done during the hospitalization.

\subsection{Measurement of lung functions and FeNO}

Lung function tests were performed on a computerized spirometer (MasterScreen, Leibnizstrasse, Hoechberg, Germany). The examination parameters included forced vital capacity (FVC), forced expiratory volume in 1 second $\left(\mathrm{FEV}_{1}\right)$, peak expiratory flow (PEF) percentage predictors' parameters (\%FVC, \%FEV 1 and \%PEF) and the $\mathrm{FEV}_{1} / \mathrm{FVC}$ ratio. Fractional exhaled nitric oxide (FeNO) measurement (NioxMino, Acerocrine, Sweden) were performed prior to bronchial provocation at a flow rate of $50 \mathrm{~mL} / \mathrm{s}$ using signals fed back for the control.

\subsection{Statistical analysis}

Parametric quantitative data were expressed as mean \pm standard deviation and non-parametric quantitative data were expressed as median (interquartile range). For Parametric quantitative data, ordinary one-way ANOVA was applied for comparison of three groups and student t-test was used for two-group comparison. For non-parametric data, differences of the three groups were analyzed using the non-parametric Kruskall-Wallis test and Mann-Whitney test was used for comparison between two groups. Spearman rho test was applied for correlation analysis. Proportions were compared between groups with chi-square tests $\left(\mathrm{c}^{2}\right)$. Optimal scaling was carried out with categorical principle component analysis. Statistical analysis was performed with SPSS 22.0 (SPSS, Chicago, IL) and GraphPad Prism 6.0 software (GraphPad Software Inc., San Diego, CA, USA). A value of $P<0.05$ was considered statistically significant.

\section{Results}

Characteristics of the study subjects were shown in Table 1. Compared with minors, adults had lower proportion of mild asthma and higher proportion of severe asthma. This resulted in worse lung function results $\left(\% \mathrm{FEV}_{1}, \mathrm{FEV}_{1} / \mathrm{FVC}\right.$ and $\left.\% \mathrm{PEF}\right)$ in adults. Besides, the number of slgE positives among minors was higher than that of adults $(4[3,5]$ vs. $2[1,5], P<0.05)$. 
Table 1

Characteristic of the study population

\section{Overall $(n=170) \quad$ Minors $(n=32) \quad$ Adults $(n=138)$}

Demographic

Age (years)

$43.99 \pm 22.52$

$6.81 \pm 3.22$

$52.34 \pm 15.38^{* *}$

Gender (male/female)

$106 / 64$

$21 / 11$

$85 / 53$

$\operatorname{BMI}\left(\mathrm{kg} / \mathrm{m}^{2}\right)$

$21.52 \pm 4.31$

$16.15 \pm 3.23$

$22.68 \pm 3.71^{* *}$

Asthma severity

Mild (\%)

$15.88 \%$

$43.75 \%$

$7.97 \%$ **

Moderate (\%)

$40.00 \%$

$25.00 \%$

$43.48 \%$

Severe (\%)

$32.35 \%$

$3.13 \%$

$39.13 \%$ **

Immunological characteristic

Total IgE levels $\left(\mathrm{kU}_{\mathrm{A}} / \mathrm{L}\right)$

$1438[1181,2255]$

$1541[1222,2494]$

$1459[1170,2279]$

Specific lgE positive rate (\%)

$78.82 \%$

$29 / 32$

109/138

Number of confirmed slgE

positivity

$3[1,5]$

$4[3,5]$

$2[1,5]^{\star}$

Use of corticoids

OCS (\%)

$34.12 \%$

$0 \%$

$42.75 \%^{* *}$

ICS (\%)

$85.88 \%$

$78.13 \%$

$86.96 \%$

Blood cell counts

WBC $\left(\times 10^{9}\right.$ cells $\left./ \mathrm{L}\right)$

$8.39[6.60,10.40]$

$8.56[6.98,11.07]$

$8.20[6.50,10.20]$

Neutrophil $\left(\times 10^{9}\right.$ cells/L)

$4.50[3.40,6.70]$

$3.75[2.90,6.63]$

$4.80[3.70,6.70]$

Eosinophil $\left(\times 10^{9}\right.$ cells/L)

$0.32[0.1,0.71]$

$0.44[0.17,0.79]$

$0.30[0.10,0.70]$

Spirometry

FVC pred (\%)

$87.50[68.35$, 99.95]

$95.00[79.12$, 111.10]

Age and BMI were given as mean \pm standard deviation, other non-parametric quantitative data were given as medians with interquartile range (IQR). BMl: body mass index; OCS: oral corticoid steroid; ICS: inhaled corticoid steroid; WBC: white blood cell; ${ }^{\star} P<0.05$ compared with Minors; ${ }^{\star \star} P<0.01$ compared with Minors 


\begin{tabular}{|c|c|c|c|}
\hline & Overall $(n=170)$ & Minors $(n=32)$ & Adults ( $n=138)$ \\
\hline $\mathrm{FEV}_{1}$ pred $(\%)$ & $\begin{array}{l}67.90[45.70 \\
90.00]\end{array}$ & $\begin{array}{l}94.40[73.37 \\
103.90]\end{array}$ & $\begin{array}{l}63.95[42.78 \\
86.93]^{\star \star}\end{array}$ \\
\hline $\mathrm{FEV}_{1} / \mathrm{FVC}$ ratio (\%) & $\begin{array}{l}66.00[52.66 \\
75.29]\end{array}$ & $81.01[77.99,88.48]$ & $\begin{array}{l}62.65[51.15 \\
71.44]^{\star \star}\end{array}$ \\
\hline PEF pred (\%) & $\begin{array}{l}72.90[47.25 \\
87.02]\end{array}$ & $\begin{array}{l}82.00[68.10 \\
108.00]\end{array}$ & $\begin{array}{l}69.00[40.05 \\
83.15]^{\star \star}\end{array}$ \\
\hline FeNO (ppb) & $\begin{array}{l}34.00[15.00 \\
64.00]\end{array}$ & $35.00[10.50,57.00]$ & $37.50[18.50,68.25]$ \\
\hline \multicolumn{4}{|l|}{ Induced sputum } \\
\hline Neutrophil (\%) & $\begin{array}{l}71.50[48.75 \\
87.50]\end{array}$ & $53.05[30.31,86.34]$ & $73.50[48.75,87.75]$ \\
\hline Eosinophil (\%) & $5.50[1.25,17.09]$ & $10.00[4.84,43.81]$ & $5.00[1.00,17.09]$ \\
\hline \multicolumn{4}{|c|}{$\begin{array}{l}\text { Age and BMI were given as mean } \pm \text { standard deviation, other non-parametric quantitative data were } \\
\text { given as medians with interquartile range (IQR). BMl: body mass index; OCS: oral corticoid steroid; } \\
\text { ICS: inhaled corticoid steroid; WBC: white blood cell; * } *<0.05 \text { compared with Minors; } * \star P<0.01 \\
\text { compared with Minors }\end{array}$} \\
\hline
\end{tabular}

We investigated the complication status in these patients (Table 2). There were 4 patients $(2.35 \%)$ complicated with conditions that may associate with serum total IgE levels $>1000 \mathrm{kU}_{\mathrm{A}} / \mathrm{L}$, which were helminthic infection (3 cases, $1.76 \%$ ) and atopic dermatitis ( 1 cases, $0.59 \%)$. In patients complicated with other conditions, airway infections (76 cases, $44.71 \%$ ) and rhinosinusitis (70 cases, $41.18 \%$ ) were the most common two complications, followed by hypertension and/or CDVs (35 cases, $20.59 \%$ ) and COPD (22 cases, 12.94\%). We further analyzed the complications in patients who were not sensitized to any detected allergens, and the pattern of complication was similar to the overall study subjects (Table S1). 
Table 2

Complication profiles of asthma patients with total $\operatorname{lgE}$ level $>1000 \mathrm{kU}_{\mathrm{A}} / \mathrm{L}$

\begin{tabular}{ll} 
Complications & Frequency $(\mathbf{n}=\mathbf{1 7 0})$ \\
\hline Asthma without complications & $24(14.12 \%)$ \\
\hline Complicated with 2 or more conditions & $68(40.00 \%)$ \\
\hline Typical conditions associated with tlgE $>1000 \mathrm{kU}_{\mathrm{A}} / \mathrm{L}$ & \\
\hline Helminthic infection & $3(1.76 \%)$ \\
\hline Atopic dermatitis & $1(0.59 \%)$ \\
\hline Other conditions & \\
\hline Airway infections & $76(44.71 \%)$ \\
\hline Rhinosinusitis & $70(41.18 \%)$ \\
\hline Hypertension and/or CDVs & $35(20.59 \%)$ \\
\hline COPD & $22(12.94 \%)$ \\
\hline Type II diabetes & $12(7.06 \%)$ \\
\hline EGPA & $10(5.88 \%)$ \\
\hline Cancer & $4(2.35 \%)$ \\
\hline ILD & $2(1.18 \%)$ \\
\hline Rheumatoid arthritis & $1(0.59 \%)$ \\
\hline
\end{tabular}

CDVs: cardiovascular diseases; COPD: chronic obstructive pulmonary disease; EGPA: eosinophilic granulomatosis with polyangiitis; ILD: interstitial lung disease.

The overlaps of complications in minors and adults were shown in Fig. 1. Only two complications were observed in minors and airway infections accounted for the most common complication in the minors group (Fig. 1A), while rhinosinusitis was the most common one in adults (Fig. 1B). In the analysis of serum total IgE levels, we performed the comparisons from various aspects, including age, asthma severity, complications, number of complications, sensitization status and number of confirmed sensitization. No significant differences were found in any of the comparison. (Fig. 2).

In the 134 patients confirmed to be sensitized to at least one allergen, we further analyzed the sensitization patterns. Overall, mites had the highest positive rate $(59.41 \%)$, followed by food $(45.29 \%)$, cockroaches (37.06\%), molds (24.71\%), animal dander (13.53\%) and pollens (11.18\%) (Fig. 3A). The sensitization patterns varied between minors and adults, where minors had significantly higher positive rates in mites $(81.25 \%$ vs. $54.35 \%, P<0.01)$ and food $(68.75 \%$ vs. $39.86 \%, P<0.01)$ compared with adults (Fig. 3B). Venn diagrams showed the profiles of poly-sensitization. In minors, nearly $90 \%$ were sensitized 
to at least 2 types of allergens and the majority were sensitized to 2 types of allergens (44.83\%), while in adults, the majority were sensitized to 1 type of allergens (26.53\%) (Fig. 3C, 3D).

Among the study subjects, serum total IgE levels were positively correlated to house dust mite specific lgE levels $(r=0.23, P<0.05)$, peripheral blood eosinophil counts $(r=0.21, P<0.01)$ and number of confirmed slgE positivity $(r=0.19, P<0.01)$ (Table $S 2)$. Besides, asthma severity was positively correlated to $A$. fumigatus specific IgE levels $(\mathrm{r}=0.200, P<0.05)$, but reversely correlated to lung function results (\%FVC: $\mathrm{r}=-0.47, P<0.01 ; \% \mathrm{FEV}_{1}: \mathrm{r}=-0.60, P<0.01 ; \mathrm{FEV}_{1} / \mathrm{FVC}: \mathrm{r}=-0.51, P<0.01$ ) (Table S2). Similarly, $A$. fumigatus specific lgE levels were also negatively associated to some of the lung function results (\%FEV $1: \mathrm{r}=-0.29, P$ $<0.01 ; \mathrm{FEV}_{1} / \mathrm{FVC}$ : $\mathrm{r}=-0.34, P<0.01$ ) (Table S2).

Results from optimal scaling illustrated a close association among lung function results, among peripheral neutrophil counts, percentage of neutrophil in sputum and white blood cell counts, between number of confirmed specific IgE positivity and house dust mite specific $\lg E$, between peripheral eosinophil counts and percentage of eosinophil in sputum, as well as between asthma severity and $A$. fumigatus specific lgE levels. (Cronbach's a =93.7\%) (Fig. 4).

In the comparison of asthma patients with different severities (Table 3), except for the lung function results, which were worsen as asthma severity increased, younger age was found in mild asthma group compared with moderate and severe group $(P<0.01)$. Similarly, mild asthma group had lower BMI compared with severe group $(P<0.05)$. Meanwhile, the peripheral blood neutrophil counts were also increased in moderate and severe asthma group compared with mild group $(P<0.05)$. Regarding complications, no significant difference was found in number of complications among the three groups $(P=0.09)$. In the mild group, lower proportion of COPD complication compared with the other two groups $(P<0.05)$. No statistical significance was found in serum total IgE levels $(P=0.84)$ and number of confirmed specific IgE positivity $(P=0.73)$ among the three groups. 
Table 3

Comparisons in asthma patients of various severity
Mild $(n=27)$
Moderate $(n=68)$
Severe $(n=55)$
$P$
value

Demographic

\begin{tabular}{|c|c|c|c|c|}
\hline Age (years) & $27.63 \pm 25.46$ & $44.41 \pm 19.74^{\star \star}$ & $51.29 \pm 16.73^{\star \star}$ & $\begin{array}{l}< \\
0.001\end{array}$ \\
\hline Gender (male/female) & $13 / 14$ & $42 / 26$ & $39 / 16$ & 0.132 \\
\hline BMI $\left(\mathrm{kg} / \mathrm{m}^{2}\right)$ & $20.00 \pm 4.48$ & $21.45 \pm 3.94$ & $22.92 \pm 3.85^{\star \star}$ & 0.009 \\
\hline \multicolumn{5}{|l|}{ Spirometry } \\
\hline FVC pred (\%) & $\begin{array}{l}106.9[94.25 \\
116.70]\end{array}$ & $\begin{array}{l}88.42[76.16 \\
100.10]^{\star \star+}\end{array}$ & $\begin{array}{l}74.50[62.20 \\
91.00]^{\star \star}\end{array}$ & $\dot{0.001}$ \\
\hline $\mathrm{FEV}_{1}$ pred (\%) & $\begin{array}{l}96.05[93.63 \\
107.80]\end{array}$ & $\begin{array}{l}73.76[52.50 \\
90.00]^{\star *+\dagger}\end{array}$ & $\begin{array}{l}50.00[33.60 \\
65.70]^{\star \star}\end{array}$ & ¿. 001 \\
\hline $\mathrm{FEV}_{1} / \mathrm{FVC}$ ratio (\%) & $\begin{array}{l}77.69[69.49, \\
86.99]\end{array}$ & $\begin{array}{l}68.60[59.00 \\
79.04]^{*+\dagger}\end{array}$ & $\begin{array}{l}54.26[41.66 \\
66.00]^{\star \star}\end{array}$ & $\begin{array}{l}<.001 \\
0.0\end{array}$ \\
\hline FeNO (ppb) & $57[20,113]$ & $34[18.50,90]$ & $38[12,52]$ & 0.369 \\
\hline
\end{tabular}

Blood cell count

WBC $\left(\times 10^{9}\right.$ cells/L)

$7.73[6.07,9.21]$

$8.53[6.70,10.46]$

$7.80[6.55,10.59]$

0.388

Eosinophil $\left(\times 10^{9}\right.$ cells $\left./ \mathrm{L}\right)$

$0.36[0.22,0.93]$

$0.30[0.03,0.72]$

$0.35[0.10,0.71]$

0.378

Neutrophil $\left(\times 10^{9}\right.$ cells/L)

$3.70[2.60,4.75]$

$4.80[3.90,7.00]^{\star}$

$4.30[3.55,6.70]^{\star}$

0.014

Induced sputum

Eosinophil (\%)

$8.00[6.00$,

48.50]

$5.50[0.94,20.88]$

$9.75[1.75,17.75]$

0.642

Neutrophil (\%)

55.60 [34.25,
$64.00]$

$64.50[45.75$,

$77.50[49.75$,

87.75]

0.198

Immunological

characteristic

Total lgE level $\left(\mathrm{kU}_{\mathrm{A}} / \mathrm{L}\right)$

1457 [1182, 2012]

$1545[1194,2288]$

$1718[1247$, 2896]

0.842

Age and $\mathrm{BMI}$ were given as mean \pm standard deviation, other non-parametric quantitative data were given as medians with interquartile range (IQR). BMl: body mass index; COPD: chronic obstructive pulmonary disease; EGPA: eosinophilic granulomatosis with polyangiitis; CDVs: Cardiovascular diseases. ${ }^{\star} P<0.05$ compared with mild asthma; ${ }^{* \star} P<0.01$ compared with mild asthma; $\uparrow P<0.05$ compared with severe asthma; $\uparrow+P<0.01$ compared with severe asthma 


\begin{tabular}{|c|c|c|c|c|}
\hline & Mild $(n=27)$ & Moderate $(n=68)$ & Severe $(n=55)$ & $\begin{array}{l}P \\
\text { value }\end{array}$ \\
\hline $\begin{array}{l}\text { Number of confirmed slgE } \\
\text { positivity }\end{array}$ & $3[1.5,5]$ & $3[1,6]$ & $2[1,5.5]$ & 0.726 \\
\hline \multicolumn{5}{|l|}{ Complications } \\
\hline Number of complications & $1[1,1]$ & $1[1,2]$ & $2[1,2]$ & 0.090 \\
\hline Airway infection (\%) & $51.85 \%$ & $44.12 \%$ & $30.91 \%$ & 0.142 \\
\hline Rhinosinusitis (\%) & $59.26 \%$ & $45.59 \%$ & $43.64 \%$ & 0.910 \\
\hline COPD (\%) & $0 \%$ & $13.24 \%$ & $21.82 \%$ & 0.027 \\
\hline EGPA (\%) & $0 \%$ & $8.82 \%$ & $7.27 \%$ & 0.291 \\
\hline Type II Diabetes (\%) & $0 \%$ & $8.82 \%$ & $7.27 \%$ & 0.291 \\
\hline $\begin{array}{l}\text { Hypertension and/or CDVs } \\
(\%)\end{array}$ & $7.41 \%$ & $22.06 \%$ & $21.82 \%$ & 0.223 \\
\hline \multicolumn{5}{|c|}{$\begin{array}{l}\text { Age and BMI were given as mean } \pm \text { standard deviation, other non-parametric quantitative data were } \\
\text { given as medians with interquartile range (IQR). BMI: body mass index; COPD: chronic obstructive } \\
\text { pulmonary disease; EGPA: eosinophilic granulomatosis with polyangiitis; CDVs: Cardiovascular } \\
\text { diseases. } * P<0.05 \text { compared with mild asthma; } * \star P<0.01 \text { compared with mild asthma; }+P<0.05 \\
\text { compared with severe asthma; }++P<0.01 \text { compared with severe asthma }\end{array}$} \\
\hline
\end{tabular}

\section{Discussion}

In this study, we described the profiles of comorbidity and sensitization of a typical group of asthma patients (total $\operatorname{lgE}>1000 \mathrm{kU}_{\mathrm{A}} / \mathrm{L}$ ). This is the first study investigating the clinical information in asthma patients with such high level of serum total lgE. Our results demonstrated that in these patients, less than $5 \%$ patients were complicated with conditions associated with serum total IgE level $>1000 \mathrm{kU}_{\mathrm{A}} / \mathrm{L}$ and nearly $80 \%$ patients were positive for at least one specific $\lg E$ test. Airway infections and rhinosinusitis were accounted for the most popular complications in minors and adults, respectively. Moreover, sensitization to $A$. fumigatus was associated with asthma severity.

In general, elevation of serum total IgE is usually found in allergic diseases. Extremely high level of serum total $\lg \mathrm{E}\left(>1000 \mathrm{kU}_{\mathrm{A}} / \mathrm{L}\right)$ could attribute to conditions like ABPA, helminthic infection and atopic dermatitis. Patients with ABPA were not included in our study, because it is a different entity of disease that exhibits asthma symptoms and may affects the analysis of IgE in asthma patients. Helminth infection induces strongly Th2-skewed responses in host defense, resulting in mastocytosis, eosinophilia and IgE production [24]. And in atopic dermatitis, the immune deviation towards Th2 and Th22 expansion, which also leads to generation of IgE against both exogenous and self allergens, and the persisting inflammation contributes to markedly elevated IgE level $[25,26]$. 
It has been reported that asthma accounted for $26.1 \%$ in patients with serum total IgE level $>1000 \mathrm{kU}_{\mathrm{A}} / \mathrm{L}$ in a 15-year retrospective analysis [15]. We further investigated the comorbidity of asthma patients with such high IgE level. There were only about $2 \%$ patients complicated with helminth infection or atopic dermatitis, and the highest two proportions of complications were airway infection (44.71\%) and rhinosinusitis (41.18\%). The frequency of patient complicated atopic dermatitis was low in our cohort. As patients complicated atopic dermatitis may not require hospitalization and the included patients were screened from in-patient system, the proportion might be underestimated. In patients without sensitization, only one patient complicated conditions associated with the raised total IgE (helminthic infection). Rihosinusitis and airway infections still accounted for the most common two complications. Asthma patients complicated with rhinitis, whether allergic or non-allergic, or airway infections could lead to elevation of total IgE levels because of chronic inflammation and the reactivity of IgE against microorganisms [27-30]. In addition to infection, air pollutants such as diesel exhaust particles can also impair the integrity of airway epithelium, which promotes infiltration of pathogens via the damaged epithelium, causing inflammation responses [31].Regarding other conditions such as COPD, EGPA, type II diabetes, CVDs and hypertension, studies have also observed up-regulated levels of serum total IgE in these diseases [32-36]. However, whether these diseases could affect total IgE levels remains unclear and the underlining mechanism of IgE overproduction in nonatopic asthma requires further investigation.

In the analysis of sensitization profiles, despite the difference between age groups, mites had the highest positivity overall allergens, followed by food. This may due to our study population, as the top five most sensitized allergens in southern China were house dust mite, cockroach and three types of food allergens [37]. There was no significant difference in total IgE levels between patients with and without sensitization, neither between patients with 1-2 specific IgE sensitization and more than 3 specific $\lg E$ sensitization. This suggested that the increase in sensitizations may have less impact on these total IgE level of these patients, because their IgE levels were already high.

Asthma severity is associated with various factors. Although $\operatorname{lgE}$ is the primarily responsible for both acute and chronic phase of inflammation characteristic of bronchial asthma, it is not an effective indicator of asthma severity [38]. In our study cohort, the proportion of mild asthma (15.88\%) was the lowest, and the average age was younger compared with the other two groups. There are several risk factors of severe asthma, including allergens, environmental and occupational sensitizers, smoking, aspirin sensitivity, behavior and infection [39]. As people grow, they might have higher chance as well as longer duration of exposure to the risk factors above, which could lead to chronic and/or persisted inflammation. Indeed, compared with the mild group, a higher proportion of COPD complications were observed in the moderate and severe groups, and the peripheral blood neutrophil counts were also higher. Evidences showed that non-type 2 inflammation (with/without type 2 inflammation) is likely to contribute to severe asthma, particularly the neutrophilic airway inflammation driven by type 1 responses and IFN- $\gamma$ [40]. Since there was no significant difference in serum total IgE levels, number of slgE positivity or eosinophil counts among the three groups, indicating that the type 2 inflammation was at a similar level. Hence, neutrophilic inflammation could be a major factor that increases asthma severity.

Page $12 / 22$ 
Correlation analysis showed associations between serum total lgE levels and house dust mite slgE levels. Since the majority of our study subjects were positive for mites, the markedly increased total IgE levels may partly attribute to the increase of house dust mite slgE. Additionally, we found positive correlation between asthma severity and $A$. fumigatus specific IgE levels. There is an entity of worse controlled asthma namely severe asthma with fungal sensitization (SAFS). Patients with SAFS could have similar symptoms as ABPA, even though they did not meet the diagnostic criteria of ABPA. In asthma patients sensitized to fungi, the long lasted inflammation caused by fungi leads to increase of Th2 immune responses, and as a result, the severity of asthma increases, which could even develop ABPA [16, 17]. In fact, our result of optimal scaling also showed that $A$. fumigatus specific lgE levels were related to asthma severity, and both of them were at the opposite site of lung function data in the scale, suggesting a negative correlation between these two sets of parameters. Therefore, management of these asthma patients should be focus on those sensitized to fungal allergens to prevent from developing severe asthma or ABPA.

There were several limitations in our study. First, the inclusion criteria was set as total serum IgE $>1000$ $\mathrm{kU}_{\mathrm{A}} / \mathrm{L}$, we cannot compare with patients with lower IgE levels. Second, this study was conducted in a single center in Southern China. Thus, our results may not be representable to other populations. Third, the allergen screening may not be comprehensive. However, we have screened for suspicious allergens of each patient based on their medical history and living environment. Last but not least, the cause of the rise of IgE level was not fully explained. Further studies are required to determine the underlining mechanism of markedly increased serum IgE level in asthma patients.

\section{Conclusion}

In conclusion, in asthma patients with markedly increased serum total $\operatorname{lgE}$ levels (>1000 $\mathrm{kU}_{\mathrm{A}} / \mathrm{L}$ ), the most common two complications were airway infections and rhinosinusitis despite of sensitization status. The majority were sensitized to mite allergens and house dust mite specific lgE levels partly contributed to the remarkably raised total IgE levels. In addition, $A$. fumigatus specific IgE levels were closely associated with total IgE levels and asthma severity.

\section{Abbreviations}

$\lg \mathrm{E}$

Immunoglobulin E

AHR

airway hyperresponsiveness

APCs

antigen presenting cells

A. fumigatus

Aspergillus fumigatus,

ABPA

Page $13 / 22$ 
allergic bronchopulmonary aspergillosis

BMI

body mass index

FeNO

fractional exhaled nitric oxide

GINA

Global Initiative for Asthma

COPD

chronic obstructive pulmonary disease

EGPA

eosinophilic granulomatosis with polyangiitis

CDVs

Cardiovascular diseases

FVC

forced vital capacity

$\mathrm{FEV}_{1}$

forced expiratory volume in 1 second

PEF

peak expiratory flow

RA

rheumatoid arthritis

SAFS

severe asthma with fungal sensitization

\section{Declarations}

\subsection{Ethics approval and consent to participate}

This study was reviewed and approved by the ethics committee of First affiliated hospital of Guangzhou Medical University (GYFYY-2016-73). The use of human serum samples was in accordance of legislation in China and the wishes of donors, their legal guardians or next of kin, where applicable, who had offered written informed consent to using the serum samples for future unspecified research purposes.

\subsection{Consent for publication}

Not applicable.

\subsection{Availability of data and materials}

Not applicable.

\subsection{Competing interests}


The authors declare that they have no conflicts of interest.

\subsection{Funding}

This study was funded by the National Natural Science Foundation of China (Project No.: 81871736, 81601394, 81572063), Bureau of traditional Chinese Medicine Scientific Research Project of Guangdong (Project No.: 20192048), Research Project of First Affiliated Hospital of Guangzhou Medical University (Project No.: ZH201915, ZH201818). Medical Research Fund Project of Guangdong Province (A2019224). Guangzhou Science and Technology Project of traditional Chinese Medicine and Integrated traditional Chinese and Western Medicine (20202A011017). The funders had no role in study design, data collection and analysis, decision to publish, or preparation of the manuscript. No additional external funding was received for this study.

\subsection{Authors' contributions}

Baoqing Sun conceived and designed the experiments. Ge Wu and Teng Zhang collected and analyzed the data. Ge Wu led the writing. All authors reviewed the manuscript.

\subsection{Acknowledgements}

We thank everyone that have involved in the data collection and clinical detection.

\section{References}

1 Wenzel SE. Asthma phenotypes: the evolution from clinical to molecular approaches. Nature medicine 2012;18: 716-25.

2 Loftus PA, Wise SK. Epidemiology and economic burden of asthma. International forum of allergy \& rhinology 2015;5 Suppl 1: S7-10.

32020 GINA Report, Global Strategy for Asthma Management and Prevention, Availabe at: https://ginasthma.org/wp-content/uploads/2020/04/GINA-2020-full-report_-final-_wms.pdf. Access Date: 18th Aug, 2020.2020.

4 Schatz M, Rosenwasser L. The allergic asthma phenotype. The journal of allergy and clinical immunology In practice 2014;2: 645-8; quiz 9.

5 Gould HJ, Sutton BJ. IgE in allergy and asthma today. Nature reviews Immunology 2008;8: 205-17.

6 Palomares O, Sanchez-Ramon S, Davila I, et al. dlvergEnt: How IgE Axis Contributes to the Continuum of Allergic Asthma and Anti-lgE Therapies. International journal of molecular sciences 2017;18.

7 Sears MR, Burrows B, Flannery EM, Herbison GP, Hewitt CJ, Holdaway MD. Relation between airway responsiveness and serum IgE in children with asthma and in apparently normal children. The New 
England journal of medicine 1991;325: 1067-71.

8 Burrows B, Martinez FD, Halonen M, Barbee RA, Cline MG. Association of asthma with serum IgE levels and skin-test reactivity to allergens. The New England journal of medicine 1989;320: 271-7.

9 Froidure A, Mouthuy J, Durham SR, Chanez P, Sibille Y, Pilette C. Asthma phenotypes and IgE responses. The European respiratory journal 2016;47: 304-19.

10 Davila I, Valero A, Entrenas LM, Valveny N, Herraez L, Group SS. Relationship between serum total IgE and disease severity in patients with allergic asthma in Spain. Journal of investigational allergology \& clinical immunology 2015;25: 120-7.

11 Borish L, Chipps B, Deniz Y, et al. Total serum IgE levels in a large cohort of patients with severe or difficult-to-treat asthma. Annals of allergy, asthma \& immunology : official publication of the American College of Allergy, Asthma, \& Immunology 2005;95: 247-53.

12 Apter AJ. Advances in adult asthma diagnosis and treatment in 2013. The Journal of allergy and clinical immunology 2014;133: 49-56.

13 Busse W, Corren J, Lanier BQ, et al. Omalizumab, anti-IgE recombinant humanized monoclonal antibody, for the treatment of severe allergic asthma. The Journal of allergy and clinical immunology 2001;108: 184-90.

14 Patel TR, Sur S. IgE and eosinophils as therapeutic targets in asthma. Current opinion in allergy and clinical immunology 2017;17: 42-9.

15 Tay TR, Bosco J, Aumann H, O'Hehir R, Hew M. Elevated total serum immunoglobulin E (>1000 IU/mL): implications? Internal medicine journal 2016;46: 846-9.

16 Agarwal R. Severe asthma with fungal sensitization. Current allergy and asthma reports 2011;11: 40313.

17 Wu G, Meng X, Zheng P, et al. Elevated serum levels of periostin in patients with allergic bronchopulmonary aspergillosis. Mycoses 2019;62: 780-9.

18 Shah A, Panjabi C. Allergic Bronchopulmonary Aspergillosis: A Perplexing Clinical Entity. Allergy, asthma \& immunology research 2016;8: 282-97.

19 Greenberger PA, Bush RK, Demain JG, Luong A, Slavin RG, Knutsen AP. Allergic bronchopulmonary aspergillosis. The journal of allergy and clinical immunology In practice 2014;2: 703-8.

20 Lanham JG, Elkon KB, Pusey CD, Hughes GR. Systemic vasculitis with asthma and eosinophilia: a clinical approach to the Churg-Strauss syndrome. Medicine 1984;63: 65-81. 
21 Fokkens WJ, Lund VJ, Hopkins C, et al. European Position Paper on Rhinosinusitis and Nasal Polyps 2020. Rhinology 2020;58: 1-464.

22 Mahoney EJ, Veling MC, Mims JW. Food Allergy in Adults and Children. Otolaryng Clin N Am 2011;44: 815-+.

23 Zeng G, Hu H, Zheng P, et al. The practical benefit of Phadiatop test as the first-line in vitro allergenspecific immunoglobulin $\mathrm{E}$ (slgE) screening of aeroallergens among Chinese asthmatics: a validation study. Annals of translational medicine 2018;6: 151.

24 Fitzsimmons CM, Falcone FH, Dunne DW. Helminth Allergens, Parasite-Specific IgE, and Its Protective Role in Human Immunity. Frontiers in immunology 2014;5: 61.

25 Boothe WD, Tarbox JA, Tarbox MB. Atopic Dermatitis: Pathophysiology. Adv Exp Med Bio/ 2017;1027: 21-37.

26 Furue M, Chiba T, Tsuji G, et al. Atopic dermatitis: immune deviation, barrier dysfunction, IgE autoreactivity and new therapies. Allergology international : official journal of the Japanese Society of Allergology 2017;66: 398-403.

27 Rosati MG, Peters AT. Relationships among allergic rhinitis, asthma, and chronic rhinosinusitis. American journal of rhinology \& allergy 2016;30: 44-7.

28 Stone KD, Prussin C, Metcalfe DD. IgE, mast cells, basophils, and eosinophils. The Journal of allergy and clinical immunology 2010;125: S73-80.

29 Kjaergard LL, Larsen FO, Norn S, Clementsen P, Skov PS, Permin H. Basophil-bound IgE and serum IgE directed against Haemophilus influenzae and Streptococcus pneumoniae in patients with chronic bronchitis during acute exacerbations. APMIS : acta pathologica, microbiologica, et immunologica Scandinavica 1996;104: 61-7.

30 Castillo Vizuete JA, Sastre J, Del Cuvillo Bernal A, et al. Asthma, rhinitis, and nasal polyp multimorbidities. Archivos de bronconeumologia 2019;55: 146-55.

31 Murrison LB, Brandt EB, Myers JB, Hershey GKK. Environmental exposures and mechanisms in allergy and asthma development. The Journal of clinical investigation 2019;129: 1504-15.

32 Grayson PC, Monach PA, Pagnoux C, et al. Value of commonly measured laboratory tests as biomarkers of disease activity and predictors of relapse in eosinophilic granulomatosis with polyangiitis. Rheumatology 2015;54: 1351-9.

33 Guo X, Yuan S, Liu Y, et al. Serum IgE levels are associated with coronary artery disease severity. Atherosclerosis 2016;251: 355-60. 
34 Wang X, Li Y, Li H, et al. Relationship of serum immunoglobulin levels to blood pressure and hypertension in an adult population. Journal of human hypertension 2018;32: 212-8.

35 Kalinina EP, Denisenko YK, Vitkina Tl, et al. The Mechanisms of the Regulation of Immune Response in Patients with Comorbidity of Chronic Obstructive Pulmonary Disease and Asthma. Canadian respiratory journal 2016;2016: 4503267.

36 Wang Z, Zhang $\mathrm{H}$, Shen $\mathrm{XH}$, et al. Immunoglobulin $\mathrm{E}$ and mast cell proteases are potential risk factors of human pre-diabetes and diabetes mellitus. PloS one 2011;6: e28962.

37 Luo W, Hu H, Tang W, et al. Allergen sensitization pattern of allergic adults and children in southern China: a survey based on real life data. Allergy, asthma, and clinical immunology : official journal of the Canadian Society of Allergy and Clinical Immunology 2019;15: 42.

38 Matucci A, Vultaggio A, Maggi E, Kasujee I. Is IgE or eosinophils the key player in allergic asthma pathogenesis? Are we asking the right question? Respiratory research 2018;19: 113.

39 Gibson PG, McDonald VM. Management of severe asthma: targeting the airways, comorbidities and risk factors. Internal medicine journal 2017;47: 623-31.

40 Ray A, Kolls JK. Neutrophilic Inflammation in Asthma and Association with Disease Severity. Trends in immunology 2017;38: 942-54.

\section{Figures}



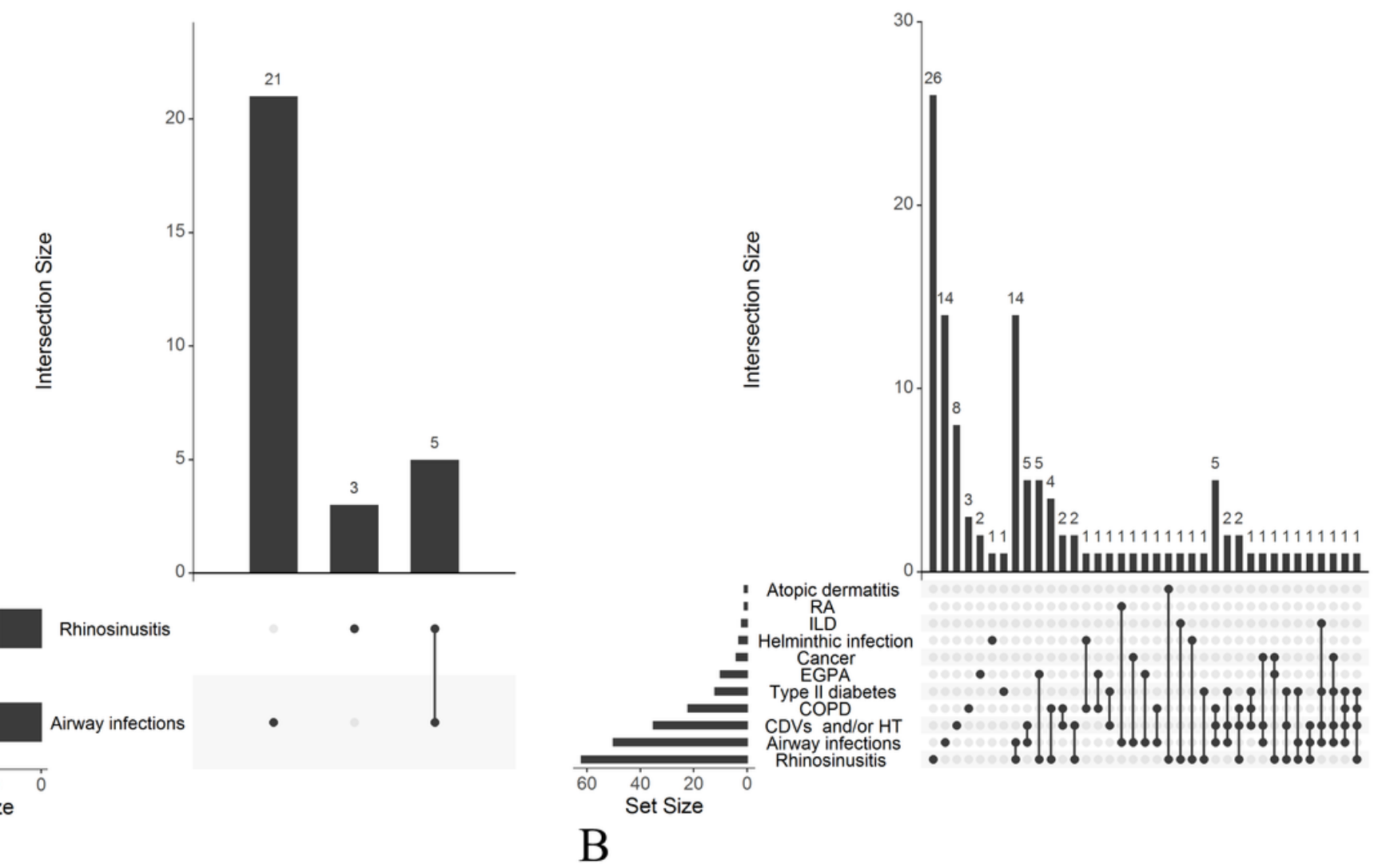

Figure 1

Complication profiles in (A) minor and (B) adult asthma patients with total lgE >1000 kUA/L. RA: rheumatoid arthritis; ILD: interstitial lung disease; EGPA: eosinophilic granulomatosis with polyangiitis; COPD: chronic obstructive pulmonary disease; CDVs: cardiovascular diseases; HT: hypertension. 


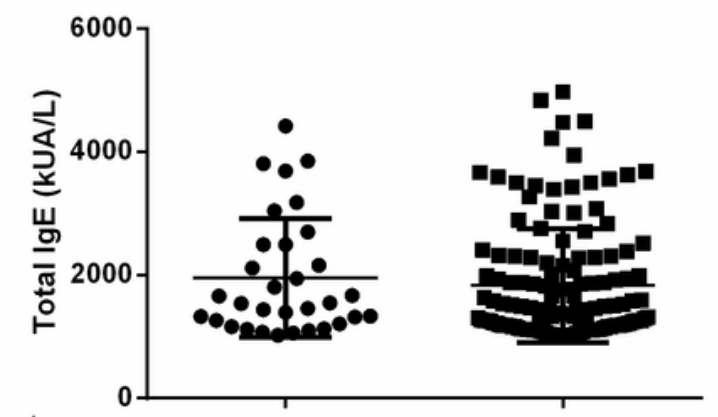

A
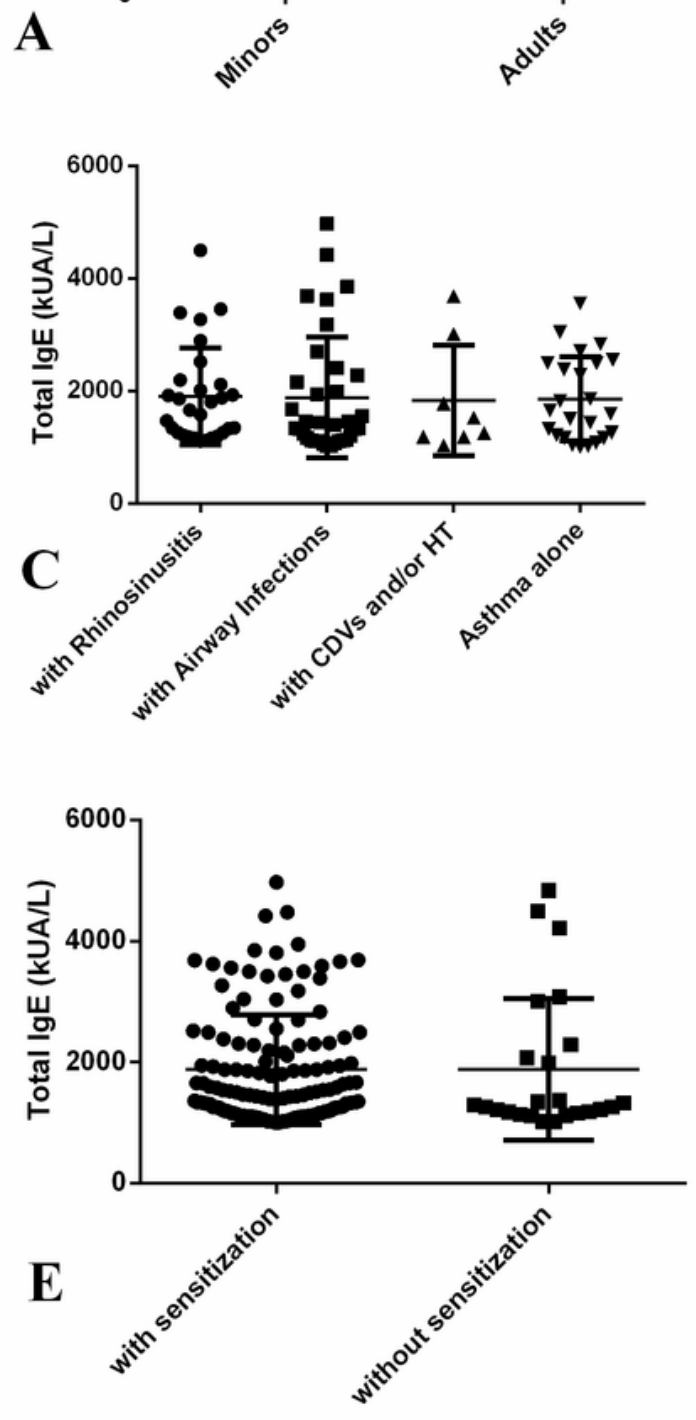
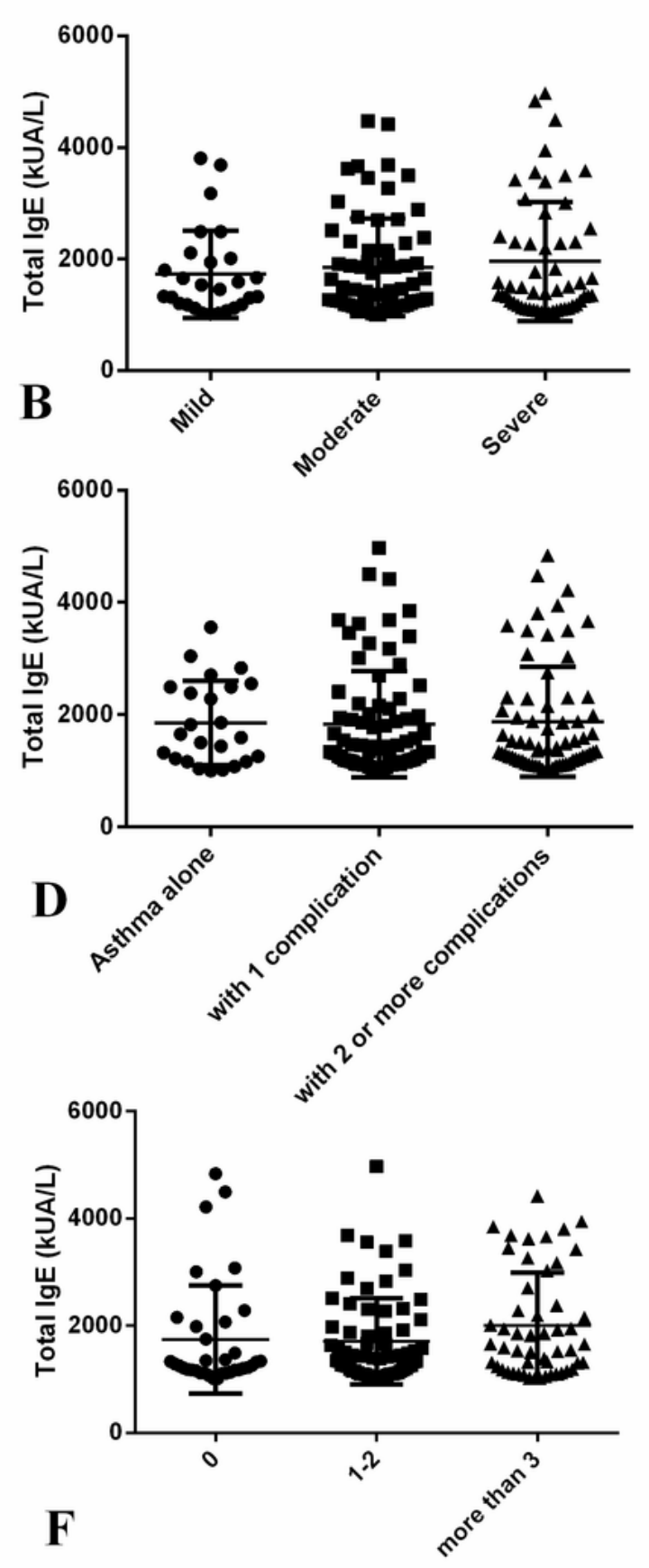

Number of confirmed sensitizations

Figure 2

Comparison of serum total lgE levels in (A) minors and adults, (B) patients with different asthma severities, (C) patients with different complications, (D) patients with different number of complications, (E) patients with and without sensitization and (F) patients with different number of sensitizations. 

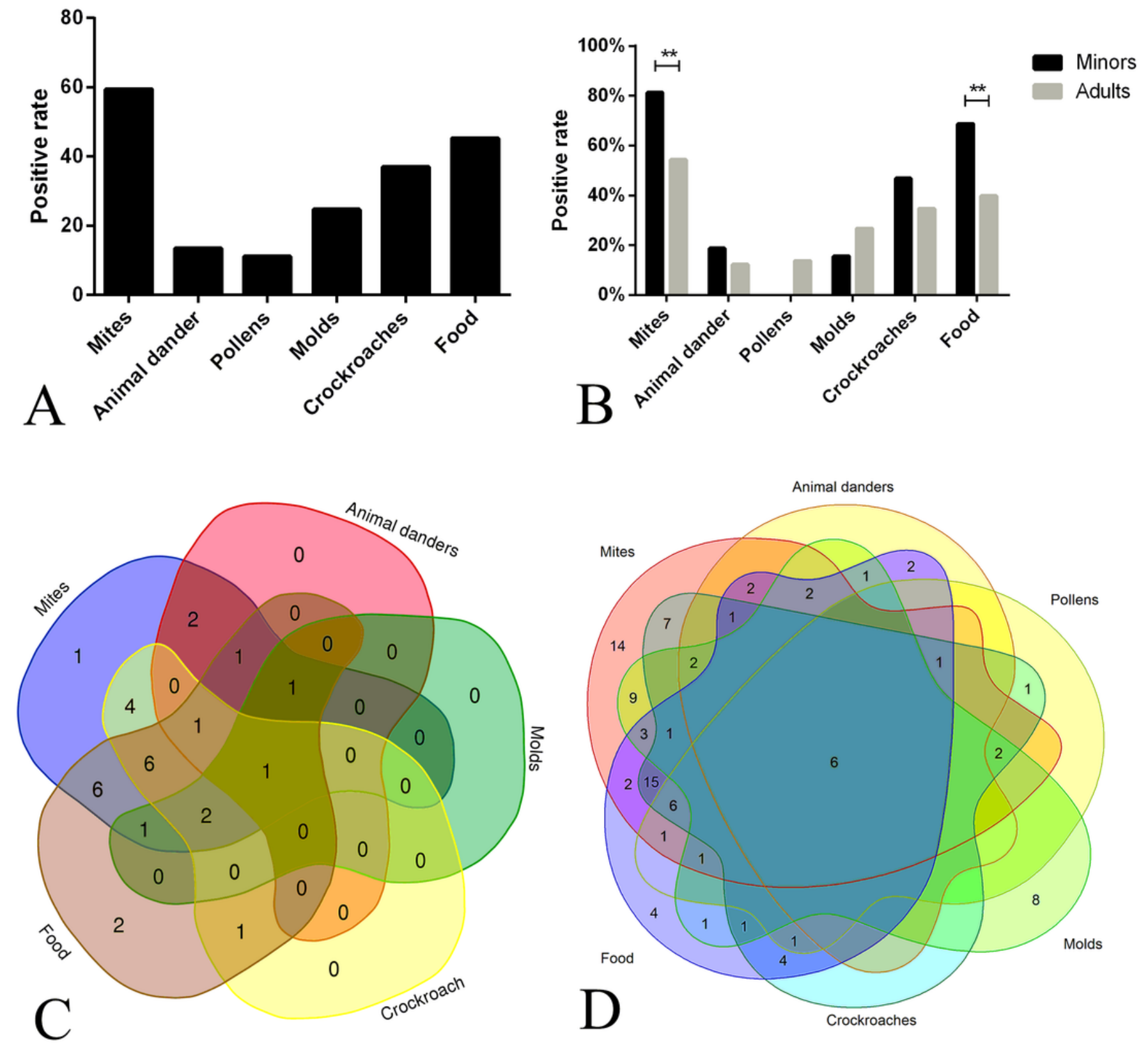

\section{Figure 3}

Sensitization profiles of asthma patients with total IgE $>1000 \mathrm{kUA} / \mathrm{L}$. (A) positive rates of 6 allergen types overall; (B) comparison of the positive rates of the 6 allergen types in minors and adults; Venn diagram showed the profiles of polysensitization in (C) minors and (D) adults. ${ }^{*} \mathrm{P}<0.01$. 


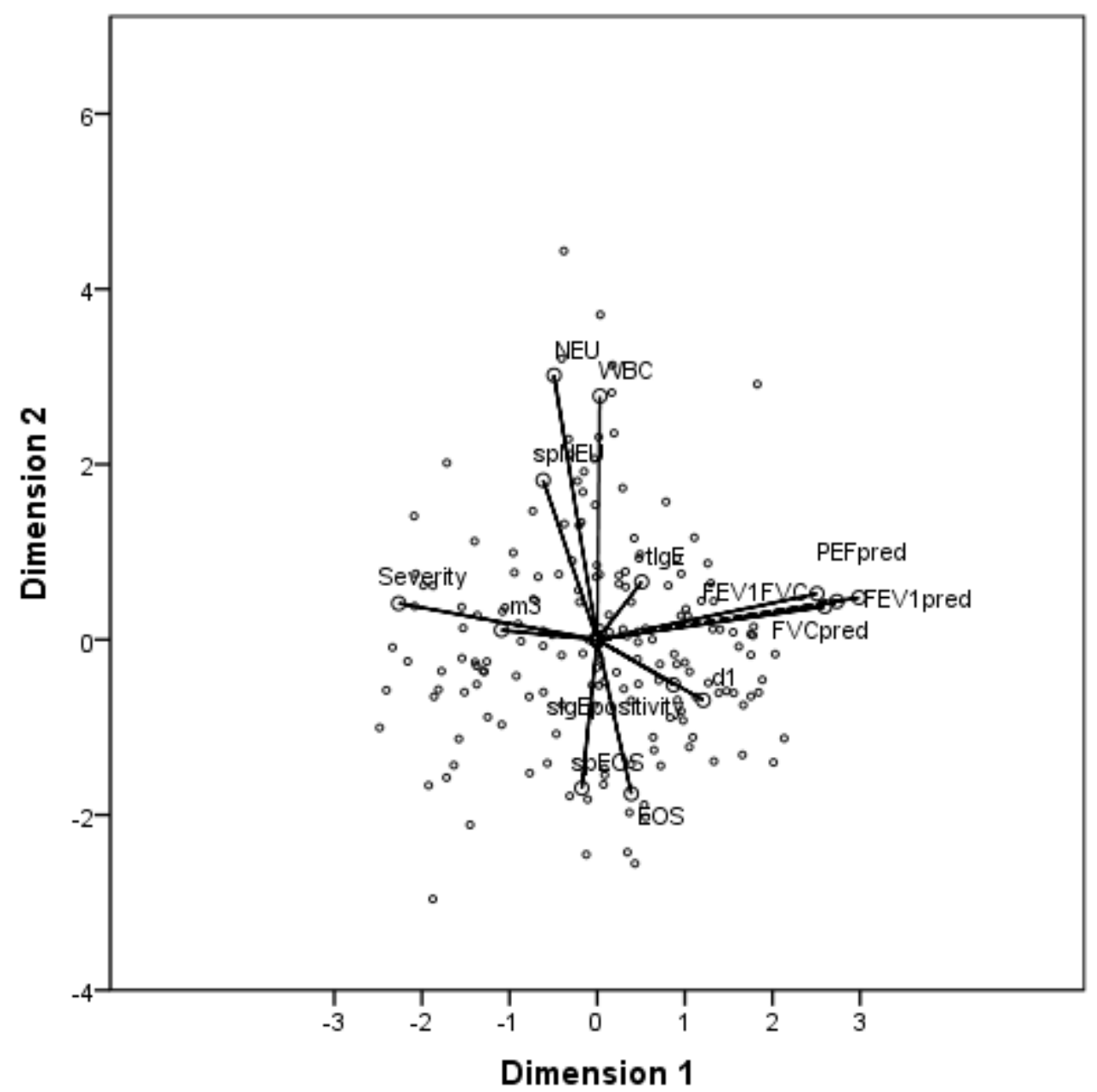

Figure 4

Optimal scale analysis of clinical data in asthma patients with total IgE $>1000 \mathrm{kUA} / \mathrm{L}$. A closer distance between the dots indicated a stronger correlation of the corresponding data (Cronbach's $a=93.7 \%)$. tlgE: total IgE; d1: house dust mite specific lgE; m3: Aspergillus fumigatus specific lgE; WBC: white blood cell; NEU: peripheral blood neutrophil counts; EOS peripheral eosinophil counts; spNEU: percentage of neutrophil in induced sputum; spEOS: percentage of eosinophil in induced sputum.

\section{Supplementary Files}

This is a list of supplementary files associated with this preprint. Click to download.

- FigureS1.pdf

- TableS1.docx

- Tables2.xls 